\title{
Hematologic disorders associated with COVID-19: a review
}

\author{
Mandeep Singh Rahi ${ }^{1}$ (1) $\cdot$ Vishal Jindal $^{2} \cdot$ Sandra-Patrucco Reyes ${ }^{3} \cdot$ Kulothungan Gunasekaran $^{1} \cdot$ Ruby Gupta $^{2}$. \\ Ishmael Jaiyesimi ${ }^{2}$
}

Received: 7 October 2020 / Accepted: 30 November 2020 / Published online: 7 January 2021

(C) The Author(s), under exclusive licence to Springer-Verlag GmbH, DE part of Springer Nature 2021

\begin{abstract}
Coronavirus disease 2019 is caused by severe acute respiratory syndrome coronavirus 2. Primarily an infection of the lower respiratory tract, it is now well known to cause multisystem abnormalities. Hematologic manifestations constitute a significant area of concern. Severe acute respiratory syndrome coronavirus 2 infects monocytes and endothelial cells leading to a complex downstream cascade, cytokine storm, and eventual intravascular thrombosis. Coronavirus disease 2019 causes lymphopenia, neutrophilia, and thrombocytopenia. Prophylactic anticoagulation is vital in patients with coronavirus disease 2019, as its effect on the coagulation system is associated with significant morbidity and mortality. The disease can cause both arterial and venous thromboses, especially pulmonary embolism and pulmonary microthrombi. A high index of suspicion is indispensable in recognizing these complications, and timely institution of therapeutic anticoagulation is vital in treating them. Virus-induced disseminated intravascular coagulation is uncommon but shares some similarities to sepsis-induced disseminated intravascular coagulation. Marked elevations in hematologic biomarkers such as lactate dehydrogenase, D-dimer, ferritin, and C-reactive protein are associated with worse outcomes. Understanding the pathophysiology and recognizing factors associated with poor prognosis are crucial in improving patient outcomes with coronavirus disease 2019.
\end{abstract}

Keywords SARS-CoV-2 · COVID-19 · Pulmonary embolism · Cytokine storm

\section{Introduction}

Coronavirus disease 2019 (COVID-19) primarily causes lower respiratory tract symptoms and pulmonary complications like acute respiratory distress syndrome (ARDS). It is now recognized as a multisystem disease with varied manifestations. Severe acute respiratory syndrome coronavirus 2 (SARS-CoV-2) is the causative organism of presumed zoonotic origin. Initially originating at the end of the year 2019 in Wuhan, China, COVID-19 has now become a pandemic

Mandeep Singh Rahi

rahi.mandeepsingh@yahoo.com

1 Division of Pulmonary Diseases and Critical Care Medicine, Yale-New Haven Health Bridgeport Hospital, 267 Grant Street, Bridgeport, CT 06610, USA

2 Division of Hematology and Oncology, William Beaumont Hospital, Oakland University, Royal Oak, MI, USA

3 Department of Internal Medicine, Yale-New Haven Health Bridgeport Hospital, Bridgeport, CT, USA infecting over 14 million people with over 600,000 deaths globally, making it a significant public health crisis.

Coronavirus belongs to the family Coronaviridae and subfamily Coronavirinae, further subdivided into four genera based on their distinct genetic properties. Several coronaviruses are known to cause significant morbidity and mortality in animals. They have a potential for animal-tohuman transmission and infect mainly the upper and lower respiratory tract in humans. The majority of infected individuals are asymptomatic or experience mild symptoms. Observational studies have reported that older adults and those with underlying respiratory and cardiovascular disease are at risk of a severe form of the disease. Nevertheless, severe illness can also occur in younger adults with no pre-existing medical conditions. Although most children are asymptomatic or have mild symptoms, recent reports have indicated that children can develop multisystem inflammatory syndrome, which carries significant mortality [1-3].

Human coronavirus is a positive-sense ribonucleic acid (RNA) virus. Severe acute respiratory syndrome (SARS) caused by severe acute respiratory syndrome coronavirus (SARS-CoV) and Middle East respiratory syndrome (MERS) caused by Middle East respiratory syndrome 
coronavirus (MERS-CoV) are the two other species responsible for fatal disease in humans. Genome sequencing of SARSCoV-2 shows $96.2 \%$ homology to a bat coronavirus. Although similar to SARS-CoV, SARS-CoV-2 has a higher affinity for the human angiotensin-converting enzyme 2 receptor (ACE-2) and faster transmission than SARS-CoV [4, 5].

Hematologic manifestations of COVID-19 were initially reported in case series and descriptive studies of COVID-19 patients from China. Although the pathogeneses remain to be elucidated, these are now widely recognized manifestations of COVID-19 and have a significant prognostic impact. Venous thromboembolism (VTE) and its complications are commonly reported in severely affected COVID-19 patients and are thought to be one of the significant contributors to increased mortality. Reports show a high incidence of VTE despite heparin thromboprophylaxis [6]. Autopsy studies have revealed microthrombi not only in pulmonary vasculature but also in other organs. This underlines the importance of effective thromboprophylaxis and the treatment of thrombotic complications in patients with COVID-19, especially those requiring intensive care. The degree of lymphopenia, thrombocytopenia, and abnormalities in the coagulation panel is heightened among COVID-10 patients who died. This highlights the importance of early recognition of anomalous hematologic findings and intervention to improve outcomes. In this review, we will explore various hematologic events, pathogenesis, biomarkers associated with adverse outcomes, and proposed management of thrombotic complications.

\section{Disorders of hemostasis: thrombosis, disseminated intravascular coagulation, and thrombocytopenia}

Hemostatic abnormalities related to COVID-19 infection are increasingly recognized. Critically ill patients are at an increased risk of venous thromboembolism (VTE) due to immobilization, systemic inflammation induced by a critical illness such as sepsis or acute pancreatitis, dehydration, endothelial dysfunction, and stasis [7]. The presence of metabolic syndrome (hypertension, diabetes, obesity), coronary artery disease, peripheral artery disease, a previous history of VTE, and hereditary thrombophilia are some of the patient-related risk factors which predispose to VTE formation [8, 9]. Infections in critically ill patients are known to cause disseminated intravascular coagulation (DIC) via endothelial damage, neutrophil activation, and activation of intravascular coagulation [10]. Sepsis-induced coagulopathy (SIC) is less severe and occurs earlier in patients with DIC. These changes are thought to be a continuum, with SIC progressing to DIC if the inciting condition is untreated [11]. The coagulopathy associated with COVID-19 meets SIC or DIC criteria in a scoring system published by the International Society on Thrombosis and Hemostasis (ISTH) in 2009 [12]. There is also a consensus that COVID-19-associated coagulopathy is more analogous to thrombotic microangiopathy and complement activation leading to endothelial damage $[9,13,14]$. Figure 1 outlines the hematologic manifestations due to COVID-19.

\section{Incidence}

COVID-19 has been implicated in both microvascular and macrovascular thrombotic complications. Pulmonary embolism (PE), deep venous thrombosis (DVT), and arterial thrombotic events like ischemic stroke have been reported [15-17]. The exact incidence of thrombotic complications is unknown, given the logistical challenges of obtaining universal computed tomography (CT) scans and the desire to limit exposure to ultrasound technicians and transport staff. Analysis of 81 patients by Cui and colleagues from China reported VTE in 20 out of 81 patients $(25 \%)$. No details about thromboprophylaxis were provided [18]. In a retrospective cohort study of 388 patients from Italy, 61 patients $(16 \%)$ required intensive care, the remaining 327 patients were admitted to general medical wards, and $78 \%$ received thromboprophylaxis. The cumulative rate of thromboembolic events was $21 \%$. Only eight patients met the criteria for overt DIC, but 7 of those died. Similar to other studies, non-survivors had rapidly increasing D-dimer levels [19]. In a recent Dutch study evaluating 184 intensive care unit (ICU) patients with COVID-19, all of whom received thromboprophylaxis, the cumulative incidence of thromboembolic events was $31 \%$. Pulmonary embolism (PE) was the most frequent thrombotic complication (81\%). Prolongation of the prothrombin time $>3 \mathrm{~s}$ and activated partial thromboplastin time $>5 \mathrm{~s}$ (adjusted hazard ratio (HR) 4.1, 95\% CI 1.99.1) were independent predictors of thrombotic complications [16]. Another Dutch study reported thromboembolic events in 35 out of $75(46.6 \%)$ patients admitted in the ICU with COVID-19 [6].

In an autopsy study of 12 patients by Wichmann and colleagues, 58\% had deep venous thrombosis (DVT). Four patients $(33 \%)$ had PE, but microthrombi were regularly seen within small lung arteries [20]. Autopsy studies from China also show diffuse microvascular thrombi in multiple organs $[14,21]$. Another series of autopsy examination of 21 patients with COVID-19 found prominent PE in four, with microthrombi in alveolar capillaries in 5 of $11(45 \%)$. Three had evidence of thrombotic microangiopathy glomerular capillaries [22]. Autopsy studies have also shown severe endothelial injury (endotheliitis) and increased angiogenesis, in addition to widespread thrombosis with microangiopathy and alveolar-capillary microthrombi in the lungs of COVID19 patients who died of the disease [23]. 


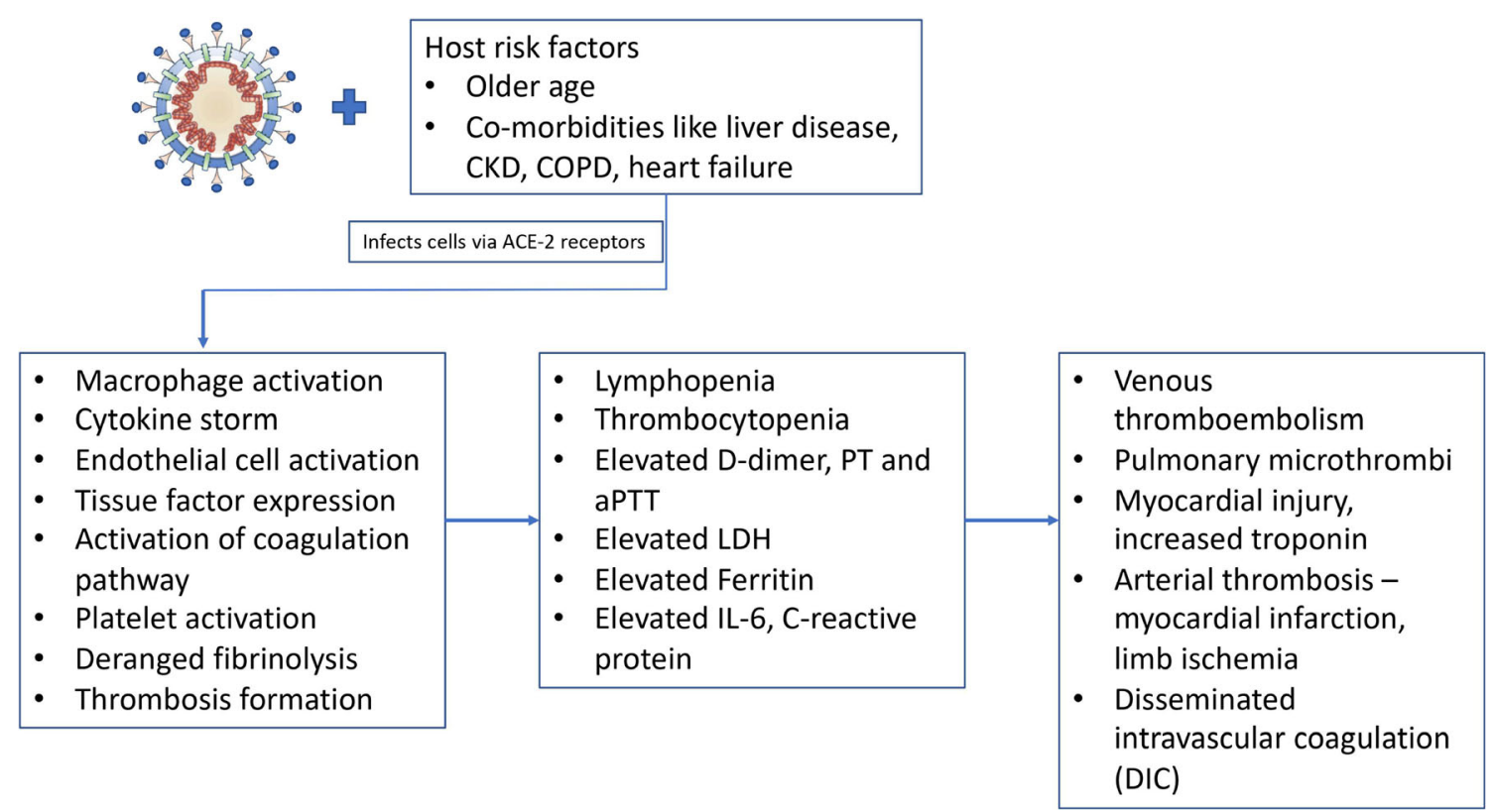

Fig. 1 The hematologic manifestations of coronavirus disease 2019

\section{Pathogenesis}

The pathophysiology of coagulopathy associated with COVID-19 is complex and not entirely delineated at present. It appears to be related to a heightened inflammatory response to viral infection rather than intrinsic to the specific viral properties of SARS-CoV-2 (Fig. 2). When compared to standard mechanisms of thrombosis in critically ill patients, there are some distinct differences in COVID-19-associated coagulopathy.

Severe SARS-CoV-2 infection leads to a profound inflammatory state through a complex interaction with macrophages/ monocytes and endothelial activation. The proposed pathway of macrophage activation and cytokine storm in COVID-19 is extrapolated from SARS-CoV. SARS-CoV-2 activates endothelial cells by ACE-2 receptors. Activated endothelial cells release chemoattractants like CCL2, CCL7, and a delayed type 1 interferon response leading to sustained recruitment of blood monocytes, which differentiate into proinflammatory macrophages. Activated natural killer (NK) cells and cytotoxic T lymphocytes (CTLs) further promote recruitment and activation of monocyte-derived macrophages through the production of granulocyte-macrophage colonystimulating factor (GM-CSF), tumor necrosis factor (TNF), and interferon- $\gamma$ (IFN- $\gamma)$. Lymphocytes express ACE- 2 receptors [24] and type 1 interferon may induce expression of

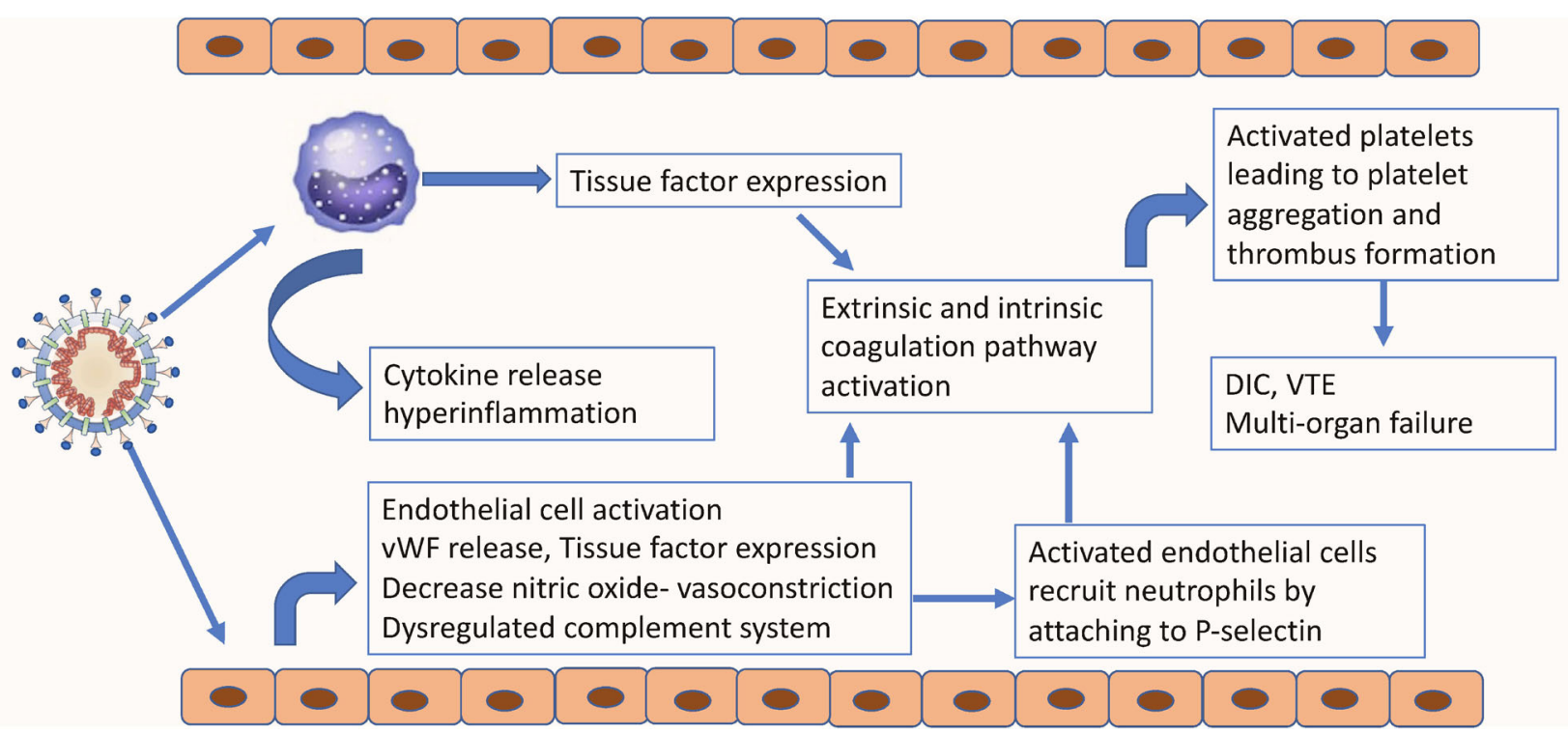

Fig. 2 The pathogenesis of thrombus generation in patients with coronavirus disease 2019 
SARS-CoV-2 entry receptors on macrophages as well. These activated monocyte-derived macrophages produce the characteristic COVID-19 cytokine storm, releasing massive amounts of pro-inflammatory cytokines including IL-6, TNF, IL-8, IL10 , and IL-1RA $[13,25-27]$. This surge in inflammatory cytokines predisposes to thrombosis in both arterial and venous circulation [28]. In severe cases, the result is hemophagocytic lymphohistiocytosis (HLH), also known as hemophagocytic syndrome (HPS).

The proposed pathway for hypercoagulation resembles closely that of SIC/DIC. Following the SARS-CoV-2 spike protein's attachment to ACE-2 receptors on the endothelial cells and release of inflammatory cytokines as described above, activated endothelial cells produce not only monocyte chemoattractants like CCL2 but also adhesion molecules like P-selectin and express tissue factor (TF). Circulating viral pathogen-associated molecular proteins (PAMPs), damageassociated molecular proteins (DAMPs), and cytokines trigger activation of blood monocytes, which leads to TF membrane expression and release of monocyte-derived microvesicles. This microvesicle release and TF expression on activated monocytes and endothelial cells lead to activation of the extrinsic coagulation pathway. Activated endothelial cells also recruit neutrophils attaching to $\mathrm{P}$-selectin and release neutrophil extracellular traps (NETs), described more completely below, which activate the intrinsic coagulation pathway [13, 25]. Furthermore, activation of endothelial cells causes reduced production of nitric oxide (NO) and von Willebrand factor (vWF) release from the Weibel-Palade body [13]. These processes together cause vasoconstriction, stasis, and platelet aggregation leading to thrombus formation. Major endogenous anticoagulant pathways, including tissue factor pathway inhibitor (TFPI), antithrombin, and protein $\mathrm{C}$, are downregulated [25]. This is in part due to intense inflammation in severe disease and hypo-fibrinolysis caused by the plasminogen activator inhibitor 1 (PAI 1) release stimulated by increased angiotensin II from SARS-CoV-2-induced ACE2 blockade [13, 27, 29].

There is an intricate interaction between the coagulation system and the complement system. NETs activate the complement system. It is postulated that SARS-CoV-2 infection also upregulates the complement system as is seen with MERS-CoV, ultimately leading to the formation of membrane attack complexes (MAC), platelet activation, and thrombosis $[13,14,27,30]$. Some believe that thrombosis in at least a subset of severe COVID-19 patients may be due to a catastrophic microvascular injury syndrome mediated by the activation of complement pathways and an associated procoagulant state [31].

There are reports of thrombotic complications in the presence of antiphospholipid antibodies [32, 33]. Likely acquired due to critical illness by SARS-CoV-2, the clinical significance of antiphospholipid antibodies in these patients is unknown. Figure 2 delineates the pathogenesis resulting in thrombosis in patients with COVID-19.

\section{Laboratory findings and prognostic implication}

Typical coagulation testing findings in COVID-19 infection include a normal or slightly prolonged prothrombin time (PT) and activated plasma thromboplastin time (aPTT) in mild disease, to marked prolongation of PT and aPTT in severe disease [34]. Platelet counts can be normal to slightly increased in mild illness and markedly reduced in severe disease [35]. Mild to marked elevations in D-dimer and fibrinogen relate to milder and severe form of the disease [36]. Although data is limited to retrospective cohort series and subgroup analysis, some of these findings have prognostic significance.

In an initial descriptive study including 1099 COVID-19 patients from China, 260 out of 560 patients $(46.4 \%)$ had Ddimer $\geq 0.5 \mu \mathrm{g} / \mathrm{mL}$, and among those with the severe disease, this elevation was more pronounced. Thrombocytopenia (platelet count $<150 \times 10^{9} / \mathrm{L}$ ) was seen in 315 out of 869 patients $(36.2 \%)$, and among those with severe disease, platelet count was markedly lower $\left(137 \times 10^{9} / \mathrm{L}\right.$ [interquartile range $\left.(\mathrm{IQR}) 99.0 \times 10^{9} / \mathrm{L}-179.5 \times 10^{9} / \mathrm{L}\right]$ vs. $172.0 \times 10^{9} / \mathrm{L}$ [IQR $\left.139.0 \times 10^{9} / \mathrm{L}-212.0 \times 10^{9} / \mathrm{L}\right] ; p<0.001$ ) [37]. In a recent systematic review, a higher D-dimer was present in patients with severe COVID-19 disease and ARDS. Nonsurvivor ARDS patients had higher D-dimer levels than the survivors [38]. In a descriptive analysis of 99 cases from China, $36 \%$ of patients had an elevated D-dimer, and $12 \%$ had developed thrombocytopenia [39]. Another retrospective analysis in 41 patients showed that those needing ICU admission had higher D-dimer and PT than those who did not need an ICU level of care. Thrombocytopenia $\left(<100 \times 10^{9} / \mathrm{L}\right)$ was only present in $5 \%$ of the patients [40].

A meta-analysis of nine studies included 1779 COVID-19 patients. It showed that platelet count was significantly lower in those with severe disease. A low platelet count was associated with an over fivefold enhanced risk of severe COVID-19 (odds ratio (OR), 5.1; 95\% CI, 1.8-14.6) [41]. A recent systematic review with 19 studies and 3383 patients found that those with severe COVID-19 had a higher degree of thrombocytopenia when compared to those with the non-severe disease [42]. In an account of 183 patients during the early phases of the pandemic, the overall mortality was $11.5 \%$. Coagulation parameters were followed for 2 weeks. $71.4 \%$ of non-survivors had overt DIC compared to $0.6 \%$ of survivors. Patients who died also had significantly higher D-dimer, longer PT, and aPTT than survivors [43]. A retrospective analysis of 81 patients by Cui and colleagues reported that a D-dimer cut-off value of $1.5 \mu \mathrm{g} / \mathrm{mL}$ predicted VTE with a sensitivity of $85.0 \%$, a specificity of $88.5 \%$, and a negative predictive value (NPV) of $94.7 \%$ [18]. Similarly, another retrospective analysis of 1449 COVID-19 patients from China 
showed higher baseline and maximum values of D-dimer, PT, and aPTT among COVID-19 patients who died. Baseline Ddimer $(\mathrm{OR}=3.18[1.48,6.82] ; p=0.003)$, change in fibrinogen $(\mathrm{OR}=6.45[1.31,31.69] ; p=0.022)$, and change in platelet count $(\mathrm{OR}=0.95[0.90-0.99] ; p=0.029)$ correlated with an increased risk of death [44]. Similar findings have been appreciated in other studies as well [45-47].

\section{Clinical manifestations}

A wide variety of thromboembolic manifestations can be noted in COVID-19 patients (Fig. 1). Diagnosis requires a high index of suspicion and sequential coagulation panels to follow changes in PT, aPTT, D-dimer, platelet count, and fibrinogen.

Venous thromboembolism (VTE), including PE and DVT, is very common in critically ill COVID-19 patients. A sudden increase in the partial pressure of arterial carbon dioxide $\left(\mathrm{PaCO}_{2}\right)$ may indicate an increase in dead-space ventilation due to pulmonary embolism. A study involving 3334 consecutive hospitalized patients with COVID-19 from New York showed that VTE was associated with an increased mortality rate (HR 1.37; 95\% CI 1.02-1.86). Most of the patients received thromboprophylaxis, and a higher D-dimer on admission $(>0.5 \mu \mathrm{g} / \mathrm{mL})$ was identified as one of the risk factors for VTE. Arterial thrombotic events, including stroke (reported in $1.6 \%$ ) and myocardial infarction (reported in $8.9 \%$ ), were associated with increased mortality (HR 1.99; 95\% CI 1.65 2.40) [48]. A single-center report from Italy described 20 patients with COVID-19 and acute limb ischemia. The incidence rate of critical limb ischemia at this center was higher when compared to that at the previous year $(16.3 \%$ vs. $1.8 \%$; $p<0.001$ ) [49].

Bleeding is less common than clotting in COVID-19. This is one of the distinctions from DIC. Typically, bleeding predominates in acute DIC and is characterized by markedly low fibrinogen and platelet count. Mildly reduced platelet count characterizes a hypercoagulable state in COVID-19, and elevated fibrinogen is more comparable to chronic or compensated DIC.

\section{Diagnosis and management}

Early diagnosis of VTE is important in COVID-19 patients. PE should be considered in COVID-19 patients with sudden deterioration of oxygenation, respiratory distress, tachycardia, unexplained hypotension, or increasing vasopressor requirement. Laboratory parameters such as a sudden rise in $\mathrm{PaCO}_{2}$ may indicate increased dead-space ventilation due to a PE. A sudden increase in D-dimer should warrant further investigation. Institutional protocols should be in place to aid with the diagnosis and management of COVID-19 patients with VTE. Computed tomography pulmonary angiogram (CTPA) and DVT ultrasonography may not be readily available due to efforts to limit COVID-19 exposure to staff members. Although operator-dependent, bedside echocardiography may be useful in diagnosing right heart failure, flattened interventricular septum, and McConnell's sign indicative of right ventricular strain. When inconclusive, a formal study should be obtained. Electrocardiogram (ECG) may show a right ventricular strain pattern in the case of PE.

The increased incidence and worse outcomes associated with the development of VTE in COVID-10 patients underline the importance of thromboprophylaxis and the aggressive management of thrombotic complications in this critically ill population (Table 1). A retrospective study, including 449 patients from China, assessed the outcomes of prophylactic heparin use. Patients with SIC score $\geq 4$ (40.0\% vs. $64.2 \%$, $p=0.029$ ) or D-dimer $>6$ times the upper limit of normal ( $32.8 \%$ vs. $52.4 \%, p=0.017)$ treated with heparin had lower 28-day mortality [50].

All hospitalized patients with COVID-19 must receive pharmacologic thromboprophylaxis with low molecular weight heparin (LMWH), fondaparinux, or unfractionated heparin (UFH). Once-daily LMWH and fondaparinux would be preferable, limiting staff contact and preserving personal protective equipment (PPE). Recent guidelines recommend against using intermediate or weight-based dosing of LMWH. Caution is advised when using direct oral anticoagulation (DOAC) for thromboprophylaxis due to hemodynamic instability and high risk of rapid deterioration, and increased incidence of acute kidney injury. Besides, many of these patients may be receiving concomitant antiviral and experimental therapies that can alter the pharmacodynamics of DOACs [51]. In patients where anticoagulants are contraindicated or are unavailable, mechanical thromboprophylaxis (e.g., pneumatic compression devices) should be used. Postdischarge thromboprophylaxis should be considered on a case-by-case basis considering the patient's severity of illness, VTE risk factors at the time of discharge, such as reduced mobility, bleeding risk, and feasibility [52]. Combined pharmacologic and mechanical prophylaxis is not recommended [53]. Many institutions have adopted intermediate-intensity or therapeutic-intensity anticoagulation protocols empirically, based on local experience. These should be implemented with caution since no high-quality data is available at the time of this writing to support higher dose pharmacologic prophylaxis.

Therapeutic anticoagulation for VTE can be achieved by the use of LMWH, UFH, or DOACs. In patients with pulmonary embolism and hypotension, who are not at high risk of bleeding, systemic thrombolytic therapy is recommended. LMWH, fondaparinux, and DOAC, unless contraindicated, may be preferable due to administration ease, limiting staff contact, and absence of need for serial monitoring. As they do not require initial parenteral anticoagulation, rivaroxaban and apixaban might be preferred over dabigatran and 
edoxaban. Anticoagulation comes with the risk of bleeding. A bleeding scoring system, such as HAS-BLED, can be used to determine the risk of bleeding in patients receiving anticoagulation and guide monitoring in high-risk patients [54]. Prothrombin complex concentrates, in addition to specific reversal agents, can be used to manage bleeding complications due to DOAC [55]. Given the lack of mortality benefit, the routine use of catheter-directed therapies during the current pandemic should be limited to critical situations. Undiscerning use of inferior vena cava filters should be avoided [52].

Management of DIC is typically focused on the treatment of the underlying condition. Unfortunately, no active pharmaceutical is currently available for the treatment of COVID-19 patients. Although uncommon, bleeding in COVID-19-associated DIC should be managed with blood products per septic coagulopathy guidelines. Platelet concentrate should be transfused to maintain a platelet count $>50 \times$ $10^{9} / \mathrm{L}$ in case of active bleeding and $>20 \times 10^{9} / \mathrm{L}$ in those at high risk of bleeding or requiring invasive procedures. Fresh frozen plasma (FFP) and cryoprecipitate should be given to actively bleeding patients with prolonged PT or aPTT and severe hypofibrinogenemia, respectively [52].

\section{Lymphopenia}

SARS-CoV-2 infection is associated with CD4+ and CD8+ T cell lymphopenia, which are thought to occur through different mechanisms [27]. It is known that SARS-CoV-2 invades human cells by binding to the angiotensinconverting enzyme 2 (ACE-2) receptor, which is primarily found in the lungs, heart, and gastrointestinal tract. These receptors are also expressed on the surface of lymphocytes. Consequently, SARS-CoV-2 may bind directly to these cells and cause lysis. Infection also results in the production and release of multiple inflammatory cytokines, as described above. This potent cytokine activation can promote lymphocyte apoptosis and lead to atrophy of lymphoid organs, thus decreasing lymphocyte regeneration [56]. Furthermore, CD4+ $\mathrm{T}$ cells play an essential role as immune modulators, including downregulation of the inflammatory response. Consequently, lymphopenia may contribute to the hyperinflammation cascade [27]. The decrease in CTLs and NK cells, which are necessary for the control of viral infection, leads to the progression of the disease [57].

Lymphopenia has been described among a large percentage of COVID-19 patients, especially those with more severe illness [56, 58-60]. In severe disease, there is a decrease in CTLs, NK cells, memory T cells, and B cells. Lower CD+ T cell levels were found to be an independent predictor of mortality [61-63]. A study evaluating the hematologic characteristics of patients admitted to Wuhan Union Hospital in China showed a significantly lower lymphocyte level and increased neutrophil-to-lymphocyte ratio in those with a critical disease than in those with severe or moderate disease. This study showed a lower mean lymphocyte count $\left(0.54 \times 10^{9} / \mathrm{L}\right)$ in those with severe disease than those with moderate disease

Table 1 Proposed anticoagulation treatment algorithm in critically ill COVID-19 patients in the intensive care units

- Patient infected with SARS-CoV-2 confirmed by polymerase chain reaction

- Closely monitor respiratory rate and oxygen saturation

- Sequential laboratory analysis of complete blood count, coagulation panel with D-dimer, PT, aPTT, liver function, and kidney function tests

- All critically ill patients should receive thromboprophylaxis with LMWH, fondaparinux, or UFH

- High index of suspicion for VTE in patients with acute worsening of respiratory failure, hemodynamic instability, increased dead space ventilation, or clinical signs of deep vein thrombosis

- Definitive diagnosis should be obtained with confirmatory tests like computed tomography pulmonary angiogram and venous ultrasonography.

- For confirmed VTE, start therapeutic anticoagulation with LMWH, fondaparinux, or UFH.

- For long term anticoagulation (three months), direct oral anticoagulation is recommended.

- Closely monitor renal function and drug-drug interactions

$S A R S-C o V-2$, severe acute respiratory syndrome coronavirus 2; $P T$, prothrombin time; $a P T T$, activated plasma thromboplastin time; $L M W H$, light molecular weight heparin; $U F H$, unfractionated heparin; VTE, venous thromboembolism 
$\left(1.2 \times 10^{9} / \mathrm{L}\right)[60]$. Additionally, a high neutrophil-tolymphocyte ratio is thought to be a result of the severe inflammatory response seen in sepsis as well as following lymphocyte destruction caused by SARS-CoV-2 [60]. Another study carried out across five hospitals in Wuhan, China, showed a lower median lymphocyte level in patients who died from COVID-19 compared to survivors [64].

Likewise, literature analysis of mostly Chinese centers found a median lymphocyte count of $0.8-1.33 \times 10^{9} / \mathrm{L}$ in mild COVID-19 disease patients, compared to $0.4-0.9 \times 10^{9} / \mathrm{L}$ in severe disease [58]. A meta-analysis, which included 18 studies and almost 3000 COVID-19 patients, showed a decreasing trend in lymphocytes between patients with severe vs. nonsevere disease and non-survival vs. survival [59]. Along with various other serum markers, lymphocyte count and the neutrophil-to-lymphocyte ratio have been proposed as prognostic factors for disease severity and outcome, and even mortality [58-60].

\section{Neutrophilia}

COVID-19-associated immune dysregulation leads to neutrophil production and lymphocyte apoptosis. Thus, neutrophilia coincides with lymphopenia, as described above $[58,65]$. Additionally, neutrophilia can be secondary to a superimposed bacterial infection, which is more likely to occur in patients with severe disease $[65,66]$.

The hyperinflammatory response and subsequent cytokine production of COVID-19 infection drive an exaggerated neutrophil, macrophage, and monocyte infiltration into the lung parenchyma [27]. Three autopsy lung samples revealed neutrophil infiltration into pulmonary capillaries, acute capillaritis with fibrin deposition, neutrophil extravasation into the alveolar space, and neutrophilic mucositis of the trachea [67].

Recently, a lesser-known neutrophil function has been proposed as a contributor to SARS-CoV-2 pathogenesis. Neutrophil extracellular traps (NETs) are web-like structures of DNA and proteins made by neutrophils and designed to entrap pathogens. The signaling mechanism which activates NETs is not entirely understood. The excessive NET formation can cause an inflammatory cascade, leading to the destruction of surrounding tissues, microthrombosis, and permanent organ damage involving the pulmonary, cardiovascular, and renal systems. This is thought to occur due to aberrant signaling during the cytokine storm in which NETs induce macrophages to secrete IL- $1 \beta$, which further enhances NET formation. Additionally, IL- $1 \beta$ induces IL6 , which can bind to soluble IL-6 receptor $\alpha$, which is shed by neutrophils, causing trans-signaling, which is associated with pro-inflammatory states [67].

Neutrophilia by itself is associated with COVID-19 disease progression, increased risk of acute respiratory distress syndrome (ARDS), and death [56, 58, 59]. The neutrophilto-lymphocyte ratio (NLR) has been used as a prognostic indicator for conditions such as acute on chronic hepatitis B liver failure [68] and as a mortality risk factor in malignancy, acute coronary syndrome, cerebral hemorrhage, among others [65]. Recent studies propose NLR as an early predictor of critical illness in SARS-CoV-2 infection. A prospective single-center study from Beijing, China, showed that NLR was the most important prognostic factor for disease progression, followed by the patient's age. They found a $50 \%$ incidence of critical illness in patients with NLR $\geq 3.13$ and aged $\geq 50$ years, with the incidence decreasing to $9.1 \%$ with an NLR of $<3.13$ and age $<50$ years [68]. Similarly, a retrospective cohort study from Wuhan University showed that higher NLR was significantly associated with an increased risk of allcause death in hospitalized COVID-19 patients [65]. The use of NLR can be quickly calculated from routine serum tests and allows clinicians to identify high-risk patients at an early stage, aids in triage to a higher level of care, and allows better allocation of medical resources to where most needed $[65,68]$.

\section{Biomarkers}

The ongoing COVID-19 pandemic has led to an urgent need for identifying serum markers of disease severity. Specific biomarkers that have emerged as useful indicators of prognosis, or even mortality, include C-reactive protein (CRP), lactate dehydrogenase (LDH), D-dimer, and ferritin (Table 2).

CRP is an acute-phase reactant induced by IL-6, produced by the liver, and is a sensitive biomarker in various inflammatory conditions, such as infection and tissue damage [66]. CRP is elevated in many patients with severe disease [66, 69]. A rise in serum CRP levels has been suggested in several studies as a reliable indicator of the presence and severity of SARS-CoV-2 infection [69-71]. A survey from Wuhan, China, found an increase in disease progression with CRP levels $>41.8 \mu \mathrm{g} / \mathrm{mL}$ [70]. Another study examined both CRP levels and lung lesions on computed tomography (CT) scan and found that CRP levels were positively correlated with the diameter of lung lesions and with the severity of illness in the early stage of COVID-19 [71]. A similar study used various characteristics to score high-resolution CT scans from COVID-19 patients at admission and later during hospitalization and found a positive correlation between $\mathrm{LDH}$, CRP, and ESR with the severity of pneumonia on initial CT [72]. Another study compared CRP levels with a CT severity score, which assigned a number according to the visual assessment of all five lung lobes, and found that CRP levels were positively correlated with CT scores. The authors proposed that CRP has a higher predictive value than a CT scan during the early stages of the disease, when CT scores may show no significant difference [73]. 
Table 2 Biomarker abnormalities associated with severe disease

Hematologic biomarkers

Coagulation biomarkers

Inflammatory biomarkers

Biochemical biomarkers
Lymphopenia (decreased T cell and B cell count)

Thrombocytopenia

Neutrophilia

Elevated prothrombin time and activated plasma thromboplastin time

Elevated D-dimer

Elevated fibrinogen (decreased in acute DIC)

Elevated erythrocyte sedimentation rate

Elevated C-reactive protein

Elevated serum ferritin

Elevated cytokines (IL-2, IL-8, IL-8, and IL-10)

Elevated cardiac enzymes (troponins, creatine kinase)

Elevated liver enzymes (aspartate and alanine aminotransferases, total bilirubin)

Elevated serum blood urea nitrogen and creatinine

$D I C$, disseminated intravascular coagulation

Lactate dehydrogenase (LDH) is an enzyme expressed in nearly all human cells, including the lungs, heart, liver, kidneys, and bone marrow, and that catalyzes the production of pyruvate to lactate [66]. Damage to any of the multiple cell types that express LDH results in increased serum LDH levels. Thus, LDH elevation is commonly seen in COVID19 patients with critical disease and is believed to indicate poor outcomes [66]. As previously mentioned, higher levels of LDH have been found to correlate with the severity of SARS-CoV-2 pneumonia [72]. It has also been observed that increasing LDH levels are associated with tissue damage and inflammation [69]. An analysis of a series of cases in Singapore showed that elevated LDH on admission, older age, and lymphopenia were associated with the need for admission to the intensive care unit (ICU) [74]. Similarly, a small study from Shenzhen, China, demonstrated a positive correlation between LDH and CRP levels with Murray scores of COVID-19 patients [75]. Overall, elevated LDH has been correlated with poor prognosis in COVID-19; however, further studies are needed.

D-dimer arises from the lysis of cross-linked fibrin and indicates the activation of coagulation and fibrinolysis [69]. D-dimer is another important biomarker examined as a potential prognostic factor of disease severity in COVID-19. An early small study looking at coagulation parameters in patients with SARS-CoV-2 pneumonia showed that those who died of COVID-19 had a significantly higher D-dimer on admission, and levels remained elevated in the late stages of the disease and in all deaths [43]. Other studies have looked at D-dimer levels as a predictor of mortality. One study found that a Ddimer $>1 \mu \mathrm{g} / \mathrm{mL}$ at admission was associated with increased odds of in-hospital death [76]. A later study found that a Ddimer level $\geq 2.0 \mu \mathrm{g} / \mathrm{mL}$ on admission was an independent factor of all-cause deaths in hospitalized patients and proposed this as an optimal cut-off to predict mortality [77]. It was noted that, compared with those with D-dimer $<2.0 \mu \mathrm{g} / \mathrm{mL}$, patients with elevated D-dimer had a higher incidence of comorbid conditions such as diabetes, hypertension, coronary artery disease, and stroke. However, an elevated D-dimer level remained a significant determinant with or without underlying disease when data was adjusted for age and gender [77].

Ferritin not only has the role of iron storage but is also a well-known acute phase reactant. Ferritin is composed of subunits $\mathrm{H}$ and $\mathrm{L}$, and synthesis is induced by different inflammatory stimuli, including cytokines such as IL-6. Notably, the production of the $\mathrm{H}$ subunit has been proposed to be driven by inflammatory stimuli, and it may function as an immunomodulatory molecule with pro-inflammatory and immunosuppressive functions [78]. A retrospective cohort study from Wuhan, China, showed that elevated ferritin, along with multiple other biomarkers such as CRP, D-dimer, LDH, neutrophilia, and lymphocytopenia, among others, was significantly associated with an increased risk of the development of ARDS. However, ferritin was not associated with mortality in this study [79]. A similar study found that serum ferritin levels of $\geq 500 \mu \mathrm{g} / \mathrm{L}$ on admission, as well as CRP and lymphocyte counts, were independent risk factors for disease severity in COVID-19 patients, with ferritin having a positive correlation with CRP and an inverse correlation with lymphocyte count [80]. The authors of another study noted that increased serum ferritin levels were observed in patients who died from COVID-19 and suggested they could be used to monitor prognosis [59]. In a meta-analysis, non-survivors had a significant increase in serum ferritin, total bilirubin, IL-6, and creatine kinase (CK) compared to survivors of COVID-19 [61]. In addition to inflammatory markers like ferritin and IL-6, myocardial injury markers are crucial in COVID-19 patient monitoring. Cardiac biomarkers, such as troponin, are elevated in patients with both severe and fatal diseases [59].

Extra-thyroidal procalcitonin synthesis is increased as a result of endotoxins and cytokines during severe bacterial 
infections. In contrast, INF- $\gamma$, which is released following viral infection, leads to downregulation of procalcitonin. Usually, procalcitonin levels remain in the reference range in non-complicated COVID-19 patients. An elevation might indicate a coexisting bacterial infection and the development of a severe form of the disease [81]. A slight increase in procalcitonin can help distinguish between COVID-19positive and COVID-19-negative patients; those with severe disease have a more marked rise in procalcitonin [82-84].

Liver and kidney function markers have also been identified as significant predictors for developing severe disease and mortality in COVID-19. Chen et al. studied a cohort of 799 patients in which concentrations of alanine aminotransferase (ALT), aspartate aminotransferase (AST), and creatinine or development of acute kidney injury were markedly increased in patients who died from COVID-19 [85]. A recent systematic review also showed that acute kidney injury was a predictor of unfavorable clinical outcomes [86].

\section{Conclusion}

In conclusion, COVID-19 is a multisystemic disorder and has prominent hematologic manifestations. It causes significant hypercoagulability with the underlying pathogenesis hypothesized to be immune-mediated. Similar to a certain extent to SIC and DIC, it carries substantial morbidity and mortality. COVID-19 causes multiple abnormalities in hematologic laboratory parameters, and some of them like D-dimer and LDH may have prognostic significance. Close monitory of laboratory parameters and a high index of suspicion are vital in formulating a tailored treatment approach for at-risk patients and may also assist with triaging high-risk patients to intensive or intermediary care units. VTE thromboprophylaxis is crucial. Therapeutic anticoagulation with UFH or LMWH should be instituted in accordance with institutional protocols and close monitoring of renal function. Early recognition of lethal complications such as DIC, PE, stroke, and limb ischemia is essential for timely intervention to improve patient outcomes. Mindful utilization of diagnostic testing for these complications is necessary. This heightened approach has the potential to improve clinical outcomes in high-risk and critically ill patients with COVID-19.

\section{Code availability Not applicable}

Authors' contributions All authors made substantial contributions to the conception or design of the work and the acquisition, analysis, or interpretation of data for the work, drafted and assisted in critical revisions to work for important intellectual content, provided final approval of the version to be published, and are in agreement to be accountable for all aspects of the work in ensuring that questions related to the accuracy or integrity of any part of the work are appropriately investigated and resolved.
Data availability Not applicable

\section{Compliance with ethical standards}

Conflict of interest The authors declare that they have no conflicts of interest.

Ethics approval Not applicable

Consent to participate Not applicable

Consent for publication Not applicable

\section{References}

1. Godfred-Cato S, Bryant B, Leung J, Oster ME, Conklin L, Abrams J, Roguski K, Wallace B, Prezzato E, Koumans EH, Lee EH, Geevarughese A, Lash MK, Reilly KH, Pulver WP, Thomas D, Feder KA, Hsu KK, Plipat N, Richardson G, Reid H, Lim S, Schmitz A, Pierce T, Hrapcak S, Datta D, Morris SB, Clarke K, Belay E (2020) COVID-19-associated multisystem inflammatory syndrome in children - United States, March-July 2020. MMWR Morb Mortal Wkly Rep 69(32):1074-1080. https://doi.org/10. 15585/mmwr.mm6932e2

2. Dufort EM, Koumans EH, Chow EJ, Rosenthal EM, Muse A, Rowlands J, Barranco MA, Maxted AM, Rosenberg ES, Easton D, Udo T, Kumar J, Pulver W, Smith L, Hutton B, Blog D, Zucker H (2020) Multisystem inflammatory syndrome in children in New York state. N Engl J Med 383(4):347-358. https://doi.org/ 10.1056/NEJMoa2021756

3. Toubiana J, Poirault C, Corsia A, Bajolle F, Fourgeaud J, Angoulvant F, Debray A, Basmaci R, Salvador E, Biscardi S, Frange P, Chalumeau M, Casanova JL, Cohen JF, Allali S (2020) Kawasaki-like multisystem inflammatory syndrome in children during the covid-19 pandemic in Paris, France: prospective observational study. Bmj 369:m2094. https://doi.org/10.1136/bmj. m2094

4. Fani M, Teimoori A, Ghafari S (2020) Comparison of the COVID2019 (SARS-CoV-2) pathogenesis with SARS-CoV and MERSCoV infections. Fut Virol 15:317-323

5. Petersen E, Koopmans M, Go U, Hamer DH, Petrosillo N, Castelli F, Storgaard M, Al Khalili S, Simonsen L (2020) Comparing SARS-CoV-2 with SARS-CoV and influenza pandemics. Lancet Infect Dis 20:e238-e244. https://doi.org/10.1016/s1473-3099(20) 30484-9

6. Beun R, Kusadasi N, Sikma M, Westerink J, Huisman A (2020) Thromboembolic events and apparent heparin resistance in patients infected with SARS-CoV-2. Int J Lab Hematol 42(Suppl 1):19-20. https://doi.org/10.1111/ijlh.13230

7. Hasan SS, Radford S, Kow CS, Zaidi STR (2020) Venous thromboembolism in critically ill COVID-19 patients receiving prophylactic or therapeutic anticoagulation: a systematic review and metaanalysis. J Thromb Thrombolysis 50(4):814-821. https://doi.org/ 10.1007/s11239-020-02235-z

8. Previtali E, Bucciarelli P, Passamonti SM, Martinelli I (2011) Risk factors for venous and arterial thrombosis. Blood Transfus 9(2): 120-138. https://doi.org/10.2450/2010.0066-10

9. Gu SX, Tyagi T, Jain K, Gu VW, Lee SH, Hwa JM, Kwan JM, Krause DS, Lee AI, Halene S, Martin KA, Chun HJ, Hwa J (2020) Thrombocytopathy and endotheliopathy: crucial contributors to COVID-19 thromboinflammation. Nat Rev Cardiol. https://doi. org/10.1038/s41569-020-00469-1 
10. Papageorgiou C, Jourdi G, Adjambri E, Walborn A, Patel P, Fareed J, Elalamy I, Hoppensteadt D, Gerotziafas GT (2018) Disseminated intravascular coagulation: an update on pathogenesis, diagnosis, and therapeutic strategies. Clin Appl Thromb Hemost 24(9_suppl):8s-28s. https://doi.org/10.1177/1076029618806424

11. Iba T, Levy JH, Raj A, Warkentin TE (2019) Advance in the management of sepsis-induced coagulopathy and disseminated intravascular coagulation. J Clin Med 8(5). https://doi.org/10.3390/ jem8050728

12. Levi M, Toh CH, Thachil J, Watson HG (2009) Guidelines for the diagnosis and management of disseminated intravascular coagulation. British Committee for Standards in Haematology. Br J Haematol 145(1):24-33. https://doi.org/10.1111/j.1365-2141. 2009.07600.x

13. Iba T, Levy JH, Connors JM, Warkentin TE, Thachil J, Levi M (2020) The unique characteristics of COVID-19 coagulopathy. Crit Care 24(1):360. https://doi.org/10.1186/s13054-020-03077-0

14. Campbell CM, Kahwash R (2020) Will complement inhibition be the new target in treating COVID-19-related systemic thrombosis? Circulation 141(22):1739-1741. https://doi.org/10.1161/ CIRCULATIONAHA.120.047419

15. Hess DC, Eldahshan W, Rutkowski E (2020) COVID-19-related stroke. Transl Stroke Res 11(3):322-325. https://doi.org/10.1007/ s12975-020-00818-9

16. Klok FA, Kruip M, van der Meer NJM, Arbous MS, Gommers D, Kant KM, Kaptein FHJ, van Paassen J, Stals MAM, Huisman MV, Endeman H (2020) Incidence of thrombotic complications in critically ill ICU patients with COVID-19. Thromb Res 191:145-147. https://doi.org/10.1016/j.thromres.2020.04.013

17. Gunasekaran K, Amoah K, Rajasurya V, Buscher MG (2020) Stroke in a young COVID-19 patient. Qjm 113(8):573-574. https://doi.org/10.1093/qjmed/hcaa177

18. Cui S, Chen S, Li X, Liu S, Wang F (2020) Prevalence of venous thromboembolism in patients with severe novel coronavirus pneumonia. J Thromb Haemost 18(6):1421-1424. https://doi.org/10. $1111 /$ jth. 14830

19. Lodigiani C, Iapichino G, Carenzo L, Cecconi M, Ferrazzi P, Sebastian T, Kucher N, Studt JD, Sacco C, Alexia B, Sandri MT, Barco S (2020) Venous and arterial thromboembolic complications in COVID-19 patients admitted to an academic hospital in Milan, Italy. Thromb Res 191:9-14. https://doi.org/10.1016/j.thromres. 2020.04.024

20. Wichmann D, Sperhake JP, Lütgehetmann M, Steurer S, Edler C, Heinemann A, Heinrich F, Mushumba H, Kniep I, Schröder AS, Burdelski C, de Heer G, Nierhaus A, Frings D, Pfefferle S, Becker $\mathrm{H}$, Bredereke-Wiedling $\mathrm{H}$, de Weerth A, Paschen HR, Sheikhzadeh-Eggers S, Stang A, Schmiedel S, Bokemeyer C, Addo MM, Aepfelbacher M, Püschel K, Kluge S (2020) Autopsy findings and venous thromboembolism in patients with COVID-19. Ann Intern Med 173:268-277. https://doi.org/10.7326/m20-2003

21. Tian S, Hu W, Niu L, Liu H, Xu H, Xiao SY (2020) Pulmonary pathology of early-phase 2019 novel coronavirus (COVID-19) pneumonia in two patients with lung cancer. J Thorac Oncol 15(5):700-704. https://doi.org/10.1016/j.jtho.2020.02.010

22. Menter T, Haslbauer JD, Nienhold R, Savic S, Hopfer H, Deigendesch N, Frank S, Turek D, Willi N, Pargger H, Bassetti S, Leuppi JD, Cathomas G, Tolnay M, Mertz KD, Tzankov A (2020) Postmortem examination of COVID-19 patients reveals diffuse alveolar damage with severe capillary congestion and variegated findings in lungs and other organs suggesting vascular dysfunction. Histopathology. 77:198-209. https://doi.org/10.1111/his. 14134

23. Ackermann M, Verleden SE, Kuehnel M, Haverich A, Welte T, Laenger F, Vanstapel A, Werlein C, Stark H, Tzankov A, Li WW, Li VW, Mentzer SJ, Jonigk D (2020) Pulmonary vascular endothelialitis, thrombosis, and angiogenesis in Covid-19. N Engl J Med 383(2):120-128. https://doi.org/10.1056/NEJMoa2015432

24. Xu H, Zhong L, Deng J, Peng J, Dan H, Zeng X, Li T, Chen Q (2020) High expression of ACE2 receptor of 2019-nCoV on the epithelial cells of oral mucosa. Int J Oral Sci 12(1):8. https://doi.org/ 10.1038/s41368-020-0074-x

25. Merad M, Martin JC (2020) Pathological inflammation in patients with COVID-19: a key role for monocytes and macrophages. Nat Rev Immunol 20(6):355-362. https://doi.org/10.1038/s41577-0200331-4

26. Connors JM, Levy JH (2020) COVID-19 and its implications for thrombosis and anticoagulation. Blood 135(23):2033-2040. https:// doi.org/10.1182/blood.2020006000

27. Henry BM, Vikse J, Benoit S, Favaloro EJ, Lippi G (2020) Hyperinflammation and derangement of renin-angiotensinaldosterone system in COVID-19: a novel hypothesis for clinically suspected hypercoagulopathy and microvascular immunothrombosis. Clin Chim Acta 507:167-173. https://doi. org/10.1016/j.cca.2020.04.027

28. Aryal MR, Gosain R, Donato A, Pathak R, Bhatt VR, Katel A, Kouides P (2020) Venous thromboembolism in COVID-19: towards an ideal approach to thromboprophylaxis, screening, and treatment. Curr Cardiol Rep 22(7):52. https://doi.org/10.1007/ s11886-020-01327-9

29. Richardson MA, Gupta A, O'Brien LA, Berg DT, Gerlitz B, Syed S, Sharma GR, Cramer MS, Heuer JG, Galbreath EJ, Grinnell BW (2008) Treatment of sepsis-induced acquired protein C deficiency reverses angiotensin-converting enzyme- 2 inhibition and decreases pulmonary inflammatory response. J Pharmacol Exp Ther 325(1): 17-26. https://doi.org/10.1124/jpet.107.130609

30. Jiang Y, Zhao G, Song N, Li P, Chen Y, Guo Y, Li J, Du L, Jiang S, Guo R, Sun S, Zhou Y (2018) Blockade of the C5a-C5aR axis alleviates lung damage in hDPP4-transgenic mice infected with MERS-CoV. Emerg Microbes Infect 7(1):77-12. https://doi.org/ 10.1038/s41426-018-0063-8

31. Magro C, Mulvey JJ, Berlin D, Nuovo G, Salvatore S, Harp J, Baxter-Stoltzfus A, Laurence J (2020) Complement associated microvascular injury and thrombosis in the pathogenesis of severe COVID-19 infection: a report of five cases. Transl Res 220:1-13. https://doi.org/10.1016/j.trsl.2020.04.007

32. Zhang Y, Xiao M, Zhang S, Xia P, Cao W, Jiang W, Chen H, Ding $\mathrm{X}$, Zhao H, Zhang H, Wang C, Zhao J, Sun X, Tian R, Wu W, Wu D, Ma J, Chen Y, Zhang D, Xie J, Yan X, Zhou X, Liu Z, Wang J, Du B, Qin Y, Gao P, Qin X, Xu Y, Zhang W, Li T, Zhang F, Zhao Y, Li Y, Zhang S (2020) Coagulopathy and antiphospholipid antibodies in patients with Covid-19. N Engl J Med 382(17):e38. https://doi.org/10.1056/NEJMc2007575

33. Bowles L, Platton S, Yartey N, Dave M, Lee K, Hart DP, MacDonald V, Green L, Sivapalaratnam S, Pasi KJ, MacCallum P (2020) Lupus anticoagulant and abnormal coagulation tests in patients with Covid-19. N Engl J Med 383(3):288-290. https:// doi.org/10.1056/NEJMc2013656

34. Aggarwal M, Dass J, Mahapatra M (2020) Hemostatic abnormalities in COVID-19: an update. Indian J Hematol Blood Transfus 36(4):1-11. https://doi.org/10.1007/s12288-020-01328-2

35. Wool GD, Miller JL (2020) The impact of COVID-19 disease on platelets and coagulation. Pathobiology. https://doi.org/10.1159/ 000512007

36. Long H, Nie L, Xiang X, Li H, Zhang X, Fu X, Ren H, Liu W, Wang Q, Wu Q (2020) D-dimer and prothrombin time are the significant indicators of severe COVID-19 and poor prognosis. Biomed Res Int 2020:6159720-6159710. https://doi.org/10.1155/ 2020/6159720

37. Guan W-j, Ni Z-y, Hu Y, Liang W-h, Ou C-q, He J-x, Liu L, Shan H, Lei C-1, Hui DSC, Du B, Li L-j, Zeng G, Yuen K-Y, Chen R-c, Tang C-1, Wang T, Chen P-y, Xiang J, Li S-y, Wang J-1, Liang Z-j, 
Peng Y-x, Wei L, Liu Y, Hu Y-h, Peng P, Wang J-m, Liu J-y, Chen Z, Li G, Zheng Z-j, Qiu S-q, Luo J, Ye C-j, Zhu S-y, Zhong N-s (2020) Clinical characteristics of coronavirus disease 2019 in China. N Engl J Med 382(18):1708-1720. https://doi.org/10. 1056/NEJMoa2002032

38. Vidali S, Morosetti D, Cossu E, Luisi MLE, Pancani S, Semeraro $\mathrm{V}$, Consales G (2020) D-dimer as an indicator of prognosis in SARS-CoV-2 infection: a systematic review. ERJ Open Res 6(2): 00260-02020. https://doi.org/10.1183/23120541.00260-2020

39. Chen N, Zhou M, Dong X, Qu J, Gong F, Han Y, Qiu Y, Wang J, Liu Y, Wei Y, Xia J, Yu T, Zhang X, Zhang L (2020) Epidemiological and clinical characteristics of 99 cases of 2019 novel coronavirus pneumonia in Wuhan, China: a descriptive study. Lancet 395(10223):507-513. https://doi.org/10.1016/ s0140-6736(20)30211-7

40. Huang C, Wang Y, Li X, Ren L, Zhao J, Hu Y, Zhang L, Fan G, Xu J, Gu X, Cheng Z, Yu T, Xia J, Wei Y, Wu W, Xie X, Yin W, Li H, Liu M, Xiao Y, Gao H, Guo L, Xie J, Wang G, Jiang R, Gao Z, Jin Q, Wang J, Cao B (2020) Clinical features of patients infected with 2019 novel coronavirus in Wuhan, China. Lancet 395(10223):497506. https://doi.org/10.1016/s0140-6736(20)30183-5

41. Lippi G, Plebani M, Henry BM (2020) Thrombocytopenia is associated with severe coronavirus disease 2019 (COVID-19) infections: a meta-analysis. Clin Chim Acta 506:145-148. https://doi. org/10.1016/j.cca.2020.03.022

42. Bashash D, Hosseini-Baharanchi FS, Rezaie-Tavirani M, Safa M, Akbari Dilmaghani N, Faranoush M, Abolghasemi H (2020) The prognostic value of thrombocytopenia in COVID-19 patients; a systematic review and meta-analysis. Arch Acad Emerg Med 8(1)

43. Tang N, Li D, Wang X, Sun Z (2020) Abnormal coagulation parameters are associated with poor prognosis in patients with novel coronavirus pneumonia. J Thromb Haemost 18(4):844-847. https:// doi.org/10.1111/jth.14768

44. Li Q, Cao Y, Chen L, Wu D, Yu J, Wang H, He W, Chen L, Dong F, Chen W, Chen W, Li L, Ran Q, Liu Q, Ren W, Gao F, Chen Z, Gale RP, Hu Y (2020) Hematological features of persons with COVID-19. Leukemia 34(8):2163-2172. https://doi.org/10.1038/ s41375-020-0910-1

45. Letícia de Oliveira Toledo S, Sousa Nogueira L, das Graças Carvalho M, Romana Alves Rios D, de Barros Pinheiro M (2020) COVID-19: review and hematologic impact. Clin Chim Acta 510: 170-176. https://doi.org/10.1016/j.cca.2020.07.016

46. Pereyra D, Heber S, Jilma B, Zoufaly A, Assinger A (2020) Routine haematological parameters in COVID-19 prognosis. Lancet Haematol 7(10):e709. https://doi.org/10.1016/s2352-3026(20) 30286-6

47. Yu B, Li X, Chen J, Ouyang M, Zhang H, Zhao X, Tang L, Luo Q, Xu M, Yang L, Huang G, Liu X, Tang J (2020) Evaluation of variation in D-dimer levels among COVID-19 and bacterial pneumonia: a retrospective analysis. J Thromb Thrombolysis 50(3): 548-557. https://doi.org/10.1007/s11239-020-02171-y

48. Bilaloglu S, Aphinyanaphongs Y, Jones S, Iturrate E, Hochman J, Berger JS (2020) Thrombosis in hospitalized patients with COVID19 in a New York City health system. Jama. 324:799-801. https:// doi.org/10.1001/jama.2020.13372

49. Bellosta R, Luzzani L, Natalini G, Pegorer MA, Attisani L, Cossu LG, Ferrandina C, Fossati A, Conti E, Bush RL, Piffaretti G (2020) Acute limb ischemia in patients with COVID-19 pneumonia. $\mathrm{J}$ Vasc Surg 72:1864-1872. https://doi.org/10.1016/j.jvs.2020.04. 483

50. Tang N, Bai H, Chen X, Gong J, Li D, Sun Z (2020) Anticoagulant treatment is associated with decreased mortality in severe coronavirus disease 2019 patients with coagulopathy. J Thromb Haemost 18(5):1094-1099. https://doi.org/10.1111/jth.14817

51. Moores LK, Tritschler T, Brosnahan S, Carrier M, Collen JF, Doerschug K, Holley AB, Jimenez D, Le Gal G, Rali P, Wells P
(2020) Prevention, diagnosis, and treatment of VTE in patients with coronavirus disease 2019: CHEST guideline and expert panel report. Chest 158(3):1143-1163. https://doi.org/10.1016/j.chest. 2020.05.559

52. Bikdeli B, Madhavan MV, Jimenez D, Chuich T, Dreyfus I, Driggin E, Nigoghossian C, Ageno W, Madjid M, Guo Y, Tang LV, Hu Y, Giri J, Cushman M, Quéré I, Dimakakos EP, Gibson CM, Lippi G, Favaloro EJ, Fareed J, Caprini JA, Tafur AJ, Burton JR, Francese DP, Wang EY, Falanga A, McLintock C, Hunt BJ, Spyropoulos AC, Barnes GD, Eikelboom JW, Weinberg I, Schulman S, Carrier M, Piazza G, Beckman JA, Steg PG, Stone GW, Rosenkranz S, Goldhaber SZ, Parikh SA, Monreal M, Krumholz HM, Konstantinides SV, Weitz JI, Lip GYH (2020) COVID-19 and thrombotic or thromboembolic disease: implications for prevention, antithrombotic therapy, and follow-up: JACC state-of-the-art review. J Am Coll Cardiol 75(23):2950 2973. https://doi.org/10.1016/j.jacc.2020.04.031

53. Arabi YM, Al-Hameed F, Burns KEA, Mehta S, Alsolamy SJ, Alshahrani MS, Mandourah Y, Almekhlafi GA, Almaani M, Al Bshabshe A, Finfer S, Arshad Z, Khalid I, Mehta Y, Gaur A, Hawa H, Buscher H, Lababidi H, Al Aithan A, Abdukahil SAI, Jose J, Afesh LY, Al-Dawood A (2019) Adjunctive intermittent pneumatic compression for venous thromboprophylaxis. N Engl J Med 380(14):1305-1315. https://doi.org/10.1056/ NEJMoa1816150

54. Gunasekaran K, Rajasurya V, Devasahayam J, Singh Rahi M, Chandran A, Elango K, Talari G (2020) A review of the incidence diagnosis and treatment of spontaneous hemorrhage in patients treated with direct oral anticoagulants. J Clin Med 9(9). https:// doi.org/10.3390/jcm9092984

55. Kaatz S, Mahan CE, Nakhle A, Gunasekaran K, Ali M, Lavender R, Paje DG (2017) Management of elective surgery and emergent bleeding with direct oral anticoagulants. Curr Cardiol Rep 19(12): 124. https://doi.org/10.1007/s11886-017-0930-2

56. Terpos E, Ntanasis-Stathopoulos I, Elalamy I, Kastritis E, Sergentanis TN, Politou M, Psaltopoulou T, Gerotziafas G, Dimopoulos MA (2020) Hematological findings and complications of COVID-19. Am J Hematol 95(7):834-847. https://doi.org/10. 1002/ajh. 25829

57. Zhang C, Wang XM, Li SR, Twelkmeyer T, Wang WH, Zhang SY, Wang SF, Chen JZ, Jin X, Wu YZ, Chen XW, Wang SD, Niu JQ, Chen HR, Tang H (2019) NKG2A is a NK cell exhaustion checkpoint for HCV persistence. Nat Commun 10(1):1507. https://doi. org/10.1038/s41467-019-09212-y

58. Liu X, Zhang R, He G (2020) Hematological findings in coronavirus disease 2019: indications of progression of disease. Ann Hematol 1

59. Henry BM, De Oliveira MHS, Benoit S, Plebani M, Lippi G (2020) Hematologic, biochemical and immune biomarker abnormalities associated with severe illness and mortality in coronavirus disease 2019 (COVID-19): a meta-analysis. Clin Chem Lab Med (CCLM) 58(7):1021-1028. https://doi.org/10.1515/cclm-2020-0369

60. Liao D, Zhou F, Luo L, Xu M, Wang H, Xia J, Gao Y, Cai L, Wang Z, Yin P (2020) Haematological characteristics and risk factors in the classification and prognosis evaluation of COVID-19: a retrospective cohort study. Lancet Haematol

61. Ponti G, Maccaferri M, Ruini C, Tomasi A, Ozben T (2020) Biomarkers associated with COVID-19 disease progression. Crit Rev Clin Lab Sci 57(6):389-399. https://doi.org/10.1080/ 10408363.2020.1770685

62. Cossarizza A, De Biasi S, Guaraldi G, Girardis M, Mussini C (2020) SARS-CoV-2, the virus that causes COVID-19: cytometry and the new challenge for global health. Cytometry A 97(4):340343. https://doi.org/10.1002/cyto.a.24002

63. Wang F, Nie J, Wang H, Zhao Q, Xiong Y, Deng L, Song S, Ma Z, Mo P, Zhang Y (2020) Characteristics of peripheral lymphocyte 
subset alteration in COVID-19 pneumonia. J Infect Dis 221(11): 1762-1769. https://doi.org/10.1093/infdis/jiaa150

64. Li Q, Cao Y, Chen L, Wu D, Yu J, Wang H, He W, Chen L, Dong F, Chen W (2020) Hematological features of persons with COVID19. Leukemia 1-10

65. Liu Y, Du X, Chen J, Jin Y, Peng L, Wang HHX, Luo M, Chen L, Zhao Y (2020) Neutrophil-to-lymphocyte ratio as an independent risk factor for mortality in hospitalized patients with COVID-19. J Infect 81(1):e6-e12. https://doi.org/10.1016/j.jinf.2020.04.002

66. Frater JL, Zini G, d'Onofrio G, Rogers HJ (2020) COVID-19 and the clinical hematology laboratory. Int J Lab Hematol 42(S1):1118. https://doi.org/10.1111/ijlh.13229

67. Barnes BJ, Adrover JM, Baxter-Stoltzfus A, Borczuk A, CoolsLartigue J, Crawford JM, Daßler-Plenker J, Guerci P, Huynh C, Knight JS, Loda M, Looney MR, McAllister F, Rayes R, Renaud S, Rousseau S, Salvatore S, Schwartz RE, Spicer JD, Yost CC, Weber A, Zuo Y, Egeblad M (2020) Targeting potential drivers of COVID-19: neutrophil extracellular traps. J Exp Med 217(6): e20200652. https://doi.org/10.1084/jem.20200652

68. Liu J, Liu Y, Xiang P, Pu L, Xiong H, Li C, Zhang M, Tan J, Xu Y, Song R, Song M, Wang L, Zhang W, Han B, Yang L, Wang X, Zhou G, Zhang T, Li B, Wang Y, Chen Z, Wang X (2020) Neutrophil-to-lymphocyte ratio predicts critical illness patients with 2019 coronavirus disease in the early stage. J Transl Med 18(1): 206. https://doi.org/10.1186/s12967-020-02374-0

69. Kermali M, Khalsa RK, Pillai K, Ismail Z, Harky A (2020) The role of biomarkers in diagnosis of COVID-19 - a systematic review. Life Sci 254:117788. https://doi.org/10.1016/j.lfs.2020.117788

70. Liu F, Li L, Xu M, Wu J, Luo D, Zhu Y, Li B, Song X, Zhou X (2020) Prognostic value of interleukin-6, C-reactive protein, and procalcitonin in patients with COVID-19. J Clin Virol 127: 104370. https://doi.org/10.1016/j.jcv.2020.104370

71. Wang L (2020) C-reactive protein levels in the early stage of COVID-19. Med Mal Infect 50(4):332-334. https://doi.org/10. 1016/j.medmal.2020.03.007

72. Xiong Y, Sun D, Liu Y, Fan Y, Zhao L, Li X, Zhu W (2020) Clinical and high-resolution CT features of the COVID-19 infection: comparison of the initial and follow-up changes. Investig Radiol 55(6):332-339. https://doi.org/10.1097/rli. 0000000000000674

73. Tan C, Huang Y, Shi F, Tan K, Ma Q, Chen Y, Jiang X, Li X (2020) C-reactive protein correlates with computed tomographic findings and predicts severe COVID-19 early. J Med Virol 92(7): 856-862. https://doi.org/10.1002/jmv.25871

74. Fan BE, Chong VCL, Chan SSW, Lim GH, Lim KGE, Tan GB, Mucheli SS, Kuperan P, Ong KH (2020) Hematologic parameters in patients with COVID-19 infection. Am J Hematol 95(6):E131E134. https://doi.org/10.1002/ajh.25774

75. Liu Y, Yang Y, Zhang C, Huang F, Wang F, Yuan J, Wang Z, Li J, Li J, Feng C, Zhang Z, Wang L, Peng L, Chen L, Qin Y, Zhao D, Tan S, Yin L, Xu J, Zhou C, Jiang C, Liu L (2020) Clinical and biochemical indexes from 2019-nCoV infected patients linked to viral loads and lung injury. Sci China Life Sci 63(3):364-374. https://doi.org/10.1007/s11427-020-1643-8

76. Zhou F, Yu T, Du R, Fan G, Liu Y, Liu Z, Xiang J, Wang Y, Song B, Gu X, Guan L, Wei Y, Li H, Wu X, Xu J, Tu S, Zhang Y, Chen
H, Cao B (2020) Clinical course and risk factors for mortality of adult inpatients with COVID-19 in Wuhan, China: a retrospective cohort study. Lancet 395(10229):1054-1062. https://doi.org/10. 1016/S0140-6736(20)30566-3

77. Zhang L, Yan X, Fan Q, Liu H, Liu X, Liu Z, Zhang Z (2020) Ddimer levels on admission to predict in-hospital mortality in patients with Covid-19. J Thromb Haemost 18(6):1324-1329. https://doi. org/10.1111/jth.14859

78. Gómez-Pastora J, Weigand M, Kim J, Wu X, Strayer J, Palmer AF, Zborowski M, Yazer M, Chalmers JJ (2020) Hyperferritinemia in critically ill COVID-19 patients - is ferritin the product of inflammation or a pathogenic mediator? Clin Chim Acta 509:249-251. https://doi.org/10.1016/j.cca.2020.06.033

79. Wu C, Chen X, Cai Y, Ja X, Zhou X, Xu S, Huang H, Zhang L, Zhou X, Du C, Zhang Y, Song J, Wang S, Chao Y, Yang Z, Xu J, Zhou X, Chen D, Xiong W, Xu L, Zhou F, Jiang J, Bai C, Zheng J, Song Y (2020) Risk factors associated with acute respiratory distress syndrome and death in patients with coronavirus disease 2019 pneumonia in Wuhan, China. JAMA Intern Med 180(7):934-943. https://doi.org/10.1001/jamainternmed.2020.0994

80. Lin Z, Long F, Yang Y, Chen X, Xu L, Yang M (2020) Serum ferritin as an independent risk factor for severity in COVID-19 patients. J Infect S0163-4453(0120)30434-30435. https://doi.org/ 10.1016/j.jinf.2020.06.053

81. Lippi G, Plebani M (2020) Procalcitonin in patients with severe coronavirus disease 2019 (COVID-19): a meta-analysis. Clin Chim Acta 505:190-191. https://doi.org/10.1016/j.cca.2020.03. 004

82. Zhang G, Hu C, Luo L, Fang F, Chen Y, Li J, Peng Z, Pan H (2020) Clinical features and short-term outcomes of 221 patients with COVID-19 in Wuhan, China. J Clin Virol 127:104364. https:// doi.org/10.1016/j.jcv.2020.104364

83. Chen T, Dai Z, Mo P, Li X, Ma Z, Song S, Chen X, Luo M, Liang K, Gao S, Zhang Y, Deng L, Xiong Y (2020) Clinical characteristics and outcomes of older patients with coronavirus disease 2019 (COVID-19) in Wuhan, China (2019): a single-centered, retrospective study. J Gerontol A Biol Sci Med Sci 75:1788-1795. https:// doi.org/10.1093/gerona/glaa089

84. Chen X, Yang Y, Huang M, Liu L, Zhang X, Xu J, Geng S, Han B, Xiao J, Wan Y (2020) Differences between COVID-19 and suspected then confirmed SARS-CoV-2-negative pneumonia: a retrospective study from a single center. J Med Virol 92:1572-1579. https://doi.org/10.1002/jmv.25810

85. Chen T, Wu D, Chen H, Yan W, Yang D, Chen G, Ma K, Xu D, Yu H, Wang H, Wang T, Guo W, Chen J, Ding C, Zhang X, Huang J, Han M, Li S, Luo X, Zhao J, Ning Q (2020) Clinical characteristics of 113 deceased patients with coronavirus disease 2019: retrospective study. Bmj 368:m1091. https://doi.org/10.1136/bmj.m1091

86. Chen YT, Shao SC, Lai EC, Hung MJ, Chen YC (2020) Mortality rate of acute kidney injury in SARS, MERS, and COVID-19 infection: a systematic review and meta-analysis. Crit Care 24(1):439. https://doi.org/10.1186/s13054-020-03134-8

Publisher's note Springer Nature remains neutral with regard to jurisdictional claims in published maps and institutional affiliations. 